\title{
IDENTIFIKASI KAWASAN PERMUKIMAN PENDUKUNG: ANALISIS PROXIMITY PENGEMBANGAN DESTINASI WISATA DANAU TOBA
}

\author{
Andreas Agung Widhijanto ${ }^{1)}$, Esti Yulitriani Tisnaningtyas ${ }^{2)}$ \\ Universitas Pandanaran \\ Jalan Banjarsari Barat No.1 Pedalangan, Banyumanik, Semarang, Indonesia \\ email $^{1)}$ : andreas.widhiyanto@gmail.com \\ email ${ }^{2)}$ : esty.yulitriani@gmail.com
}

\begin{abstract}
ABSTRAK
Danau Toba dengan 3 (tiga) komponen wisata yaitu wisata alami danau, wisata geopark atau taman bumi dan wisata budaya daerah (Batak)menjadi daerah tujuan wisata. Teori siklus hidup destinasi pariwisata menunjukkan bahwa kehidupan kegiatan kepariwisataan Danau Toba mengalami peningkatan. Hal inilah yang menjadikan Danau Toba sebagai Kawasan Strategis Pariwisata Nasional (KSPN) meliputi 7 (tujuh) Kabupaten pada tepian Danau Toba, yaitu Toba Samosir, Samosir, Simalungun, Tapanuli Utara, Karo, Humbang Hasundutan, dan Dairi.Tourism development atau pembangunan pariwisata yang dilakukan dengan mengembangkan konsep 3A - Attraction, Amenitiesand Accessibility (atraksi, amenitas/kenyamanan dan aksesibilitas) - menjadi parameter keberhasilan pembangunan kepariwisataan suatu daerah, termasuk kawasan pariwisata Danau Toba.

Riset yang dilakukan ini memiliki 2 (dua) pertanyaan riset. Pertama adalah bagaimana menganalisis hasil identifikasi kawasan permukiman pendukung kepariwisataan Danau Toba, sedangkan kedua adalah bagaimana konsep untuk menjawab kebutuhan pengembangan Destinasi Wisata Danau Toba. Kerangka Riset ini dialurkan dalam variable berdasar atas indikator yang dihasilkan melalui rangkuman kajian-kajian. Selanjutnya akanditajamkan melalui proses analisis spasial dengan menggunakan metoda proximity. Analisis dengan menggunakan metoda proximity merupakan analisis secara spasial untuk mendapatkan penentuan kawasan permukiman prioritas pendukung pariwisata Danau Toba.Penentuan ini mengunakan variable lokasi strategis, obyek wisata unggulan, tourism linkages pada obyek wisata unggulan, lokasi prioritas pendukung wisata Danau Toba dan permukiman pendukung lokasi prioritas wisata.
\end{abstract}

Kata Kunci : kawasan permukiman, destinasi wisata, danau toba, analisis proximity.

\section{PENDAHULUAN}

Kepariwisataan Danau Toba memiliki potensi wisata alami danau, wisata geopark atau taman bumi dan wisata budaya daerah (Batak). Destinasi Wisata Nasional ini menjadi salah satu unggulan dalam daya saing industri pariwisata nasional, bahkan internasional sehingga menjadi salah satu amanat pembangunan pariwisata nasional melalui Nawacita dan masuk dalam 10 Destinasi Wisata Nasional.Kawasan Wisata Danau Toba memiliki potensi wisata alam yang terbentuk dari aktifitas Supervulkanik sehingga menjadikannya sebagai geopark atau taman bumi, Penetapan warisan taman bumi (geopark) oleh UNESCO merupakan bentang pemandangan alamberupa geoarea. Siklus hidup atau pertumbuhan destinasi kepariwisataan Danau Toba berkembang pesat sebagai Daerah Tujuan Wisata (DTW) sejalan dengan meningkatnya kunjungan wisata baik domestik maupun mancanegara. Pada sisi lain peningkatan kunjungan kegiatan wisata ini tidak diikuti oleh keseimbangan lingkungan binaan pada sekitar kawasan Danau Toba seperti keberadaan permukiman, pengelolaan limbah dan pemanfaatan ruang untuk wisata.

Kawasan Strategis Pariwisata Nasional $\left(\mathrm{KSPN}^{1}\right)$ Kawasan Danau Toba berada pada

\footnotetext{
${ }^{1}$ Berdasarkan Peraturan Pemerintah No. 50 Tahun 2011 tentang Rencana Induk Pembangunan Kepariwisataan
} 
ketinggian 903 meter dpl, Danau Toba memiliki luas perairan $1.130 \mathrm{~km}^{2}$ yang merupakan daerah tangkapan air (DTA) Danau Toba lebih kurang $4.311,58 \mathrm{~km}^{2}$. Secara administratif, Kawasan Wisata Danau Toba meliputi 7 (tujuh) Kabupaten pada tepian Danau Toba, yaitu Toba Samosir, Samosir, Simalungun, Tapanuli Utara, Karo, Humbang Hasundutan, dan Dairi, sesuai dengan Struktur Ruang Sekitar Danau Toba pada RTR Kawasan Danau Toba dan sekitarnya.

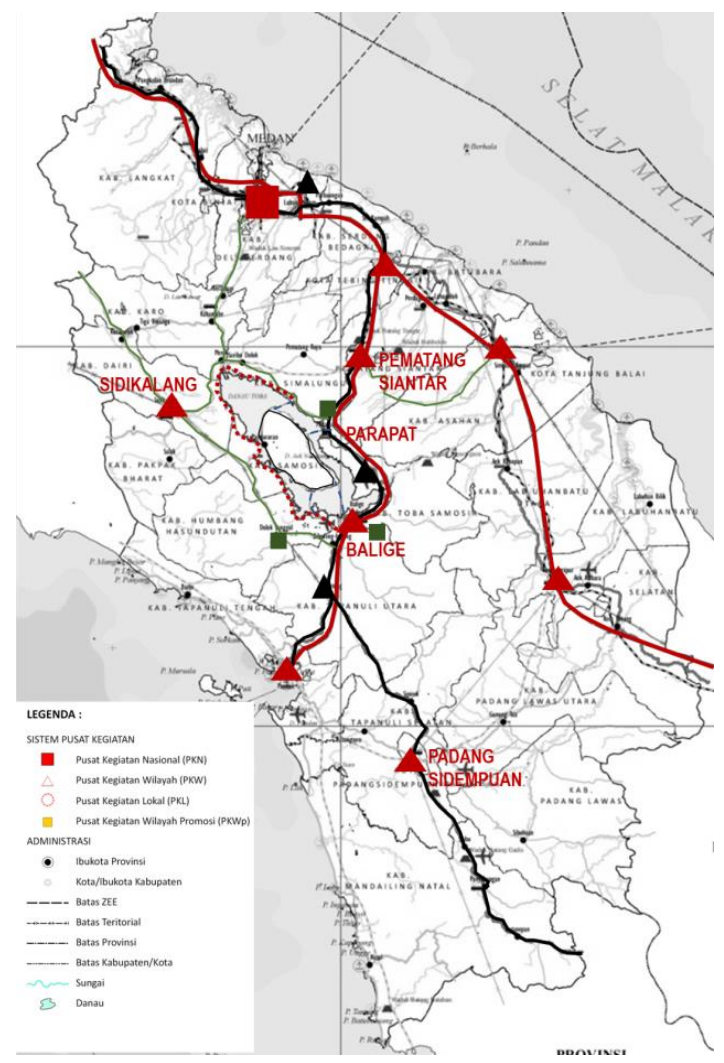

Gambar 1. Peta dengan Struktur Ruang Sekitar Danau Toba. Sumber: RTRW Provinsi Sumetera Utara

Keberadaan KSPN Danau Toba ini tidak lepas dari pertumbuhan kota-kota sekitar sebagai kota-kota layanan pariwisata.Kota-kota tersebut

Nasional Tahun 2010 - 2025 yang juga diatur dalam Peraturan Pemerintah Republik Indonesia Nomor : 26 Tahun 2008 tentang RTRWN,bahwa wilayah Danau Toba dan Sekitarnya masuk dalam golongan B/1 memiliki fungsi Rehabilitasi dan Pengembangan Kawasan Strategis Nasional Dengan Sudut Kepentingan Lingkungan Hidup. Wilayah ini khususnya ditujukan menyokong fungsi Rehabilitasi atau Revitalisasi Kawasan. menjadi tumbuh menjadi kotalayanan jasa pariwisata. Beberapa kota yang tumbuh dengan cepat seperti Kota Balige sebagai pelayanan jasa pariwisata, dengan kelas pelayanan PKW; Kota Parapat sebagai kawasan pariwisata, dengan kelas pelayanan PKL; Kota Pangururan sebagai kota pariwisata, dengan kelas pelayanan PKL.

\section{Isu-isu Generik: Tourism Develompment dan Dukungan Permukiman Wisata}

Isu-isu generik tentang tourism development atau pembangunan pariwisata menempatkan konsep 3A-Attraction, Amenitiesand Accessibility (atraksi, amenitas/kenyamanan dan aksesibilitas) menjadi parameter keberhasilan pembangunan kepariwisataan suatu daerah, termasuk kawasan pariwisata Danau Toba.Hal tersebut dilakukan untuk meningkatkan kapasitas kepariwisataan Danau Toba.Tentusaja kawasan Wisata Danau Toba menjadi lebih marketable dan memiliki peningkatan daya jual, sehingga Kawasan Wisata Danau Toba disebut sebagai Kawasan Strategis Pariwisata.Adanya geopark atau taman bumi menjadi daya tarik tersendiri berupa geoarea kaldera.

Geopark ini bertujuan untuk memelihara dan melestarikan keterkaitan/hubungan antara warisan geologi dengan semua aspek kehidupan manusia seperti warisan alam, warisan budaya di sebuah kawasan.Peningkatan kegiatan kepariwisataan Danau Toba juga mendorong timbulnya layanan jasa pariwisata pada kota-kota sekitar Danau Toba.Hal ini diikuti dengan berkembangnya aspek-aspek lingkungan binaan disekitarnya, termasuk permukiman masyarakat setempat.Dengan demikian pengembangan obyek wisata ini tidak lagi tunggal dan sangat bervariasi baik sebagai Daerah Tujuan Wisata Unggulan dan mengembangkan kawasan permukiman pendukung pariwisata KSPN Danau Toba.

\section{Pertanyaan Riset}

Pertanyaan riset dari Identifikasi Kawasan Permukiman Pendukung: Analisis Proximity Pengembangan Destinasi Wisata Danau Toba ini, pertama adalah bagaimana menganalisis hasil identifikasi kawasan permukiman pendukung kepariwisataan Danau Toba. Sedangkan pertanyaan kedua adalah bagaimana konsep dalam menjawab kebutuhan pengembangan Destinasi 
Wisata Danau Toba dengan dukungan kawasan permukiman.

\section{Tujuan dan Manfaat}

Tujuan riset ini adalah menjawab identifikasi kawasan permukiman manasaja yang dapat mendukung pengembangan Desitinasi Wisata Danau Toba. Sedangkan tujuan khusus riset ini adalah:

1. Mengidentifikasi kawasan permukiman pada pusat-pusat layanan jasa pariwisata kota-kota sekitar Danau Toba

2. Manganalisa keterkaitan jasa layanan pariwisata dengan menggunakan analisis Proximity Pengembangan Daerah Tujuan Wisata Danau Toba.

3. Merumuskan kebutuhan konsep penanganan kawasan permukiman terkait dengan kepariwisataan Danau Toba

Manfaat riset diarahkan bagi pengetahuan, agensi pembangun kepariwisataan dan secara khusus bagi masyarakat.

\section{Kerangka pelaksanaan Metoda Riset}

Kerangka Riset ini dialurkan dalam variable setelah dinilai berdasar indikator yang dihasilkan melalui rangkuman ${ }^{2}$ kajian-kajian terdahulu. Kajian terdahulu merupakan penegasan kembali sebelum ditajamkan pada proses analisis. Selanjutnya, analisis dilakukan analisis spasial sengan menggunakan metoda proximity ${ }^{3}$.Kerangka riset ini dimatrikskan dalam tahapan atau alur seperti pada tabulasi berikut ini.

\footnotetext{
${ }^{2}$ Resume ini yang akan menunjukkan karakteristik dari pengembangan Daerah Tujuan Danau Toba mencakup Lokasi Strategis, Obyek Wisata Unggulan, Tourism Linkages pada Obyek Wisata unggulan, Lokasi Prioritas Pendukung Wisata Toba dan Permukiman Pendukung Lokasi Prioritas Wisata.

${ }^{3}$ Analisa Proximity merupakan suatu geografi yang berbasis pada jarak antar layer. Dalam analisis proximity SIG menggunakan proses yang disebutdengan buffering (membangun lapisan pendukung sekitar layer dalam jaraktertentu untuk menentukan dekatnya hubungan antara sifat bagian yang ada.
}

Tabel 1. Tahapan Penentuan Kawasan Permukiman Prioritas Pendukung Pariwisata Danau Toba

\begin{tabular}{|c|c|c|c|c|}
\hline No & $\begin{array}{l}\text { Varia- } \\
\text { bel }\end{array}$ & Kriteria & Indikator & Taha-pan \\
\hline \multirow[t]{2}{*}{1} & \multirow[t]{2}{*}{$\begin{array}{l}\text { Lokasi } \\
\text { Strategis }\end{array}$} & $\begin{array}{l}\text { Berdasarkan } \\
\text { Tata Ruang }\end{array}$ & $\begin{array}{l}\text { Sesuai arahan } \\
\text { tata ruang }\end{array}$ & $\begin{array}{l}\text { Identifikas } \\
\mathrm{i}\end{array}$ \\
\hline & & $\begin{array}{l}\text { Ketersediaan } \\
\text { Bandara }\end{array}$ & $\begin{array}{ll}\text { Dekat dan } \\
\text { terakses } & \\
\text { bandara } & \\
\end{array}$ & $\begin{array}{l}\text { Identifikas } \\
\mathrm{i}\end{array}$ \\
\hline 2 & $\begin{array}{l}\text { Obyek } \\
\text { Wisata } \\
\text { Unggulan }\end{array}$ & $\begin{array}{l}\text { Overlay dari } \\
\text { dokumen } \\
\text { pengembanga } \\
\mathrm{n} \\
\text { perencanaan } \\
\text { pariwisata } \\
\text { Danau Toba }\end{array}$ & $\begin{array}{l}\text { Menjadi lokasi } \\
\text { yang diusulkan } \\
\text { oleh dua } \\
\text { dokumen: } \\
\text { RIPPARNAS } \\
\text { dan } \\
\text { Masterdevelpm } \\
\text { ent Plan }\end{array}$ & $\begin{array}{l}\text { Kajian } \\
\text { Literatur }\end{array}$ \\
\hline \multirow[t]{2}{*}{3} & \multirow{2}{*}{$\begin{array}{l}\text { Tourism } \\
\text { Linkages } \\
\text { pada } \\
\text { Obyek } \\
\text { Wisata } \\
\text { unggulan }\end{array}$} & Linkages & $\begin{array}{l}\text { Terakses jalur } \\
\text { wisata }\end{array}$ & \multirow[t]{2}{*}{$\begin{array}{l}\text { Kajian } \\
\text { Pemetaan }\end{array}$} \\
\hline & & $\begin{array}{l}\text { Interchange } \\
\text { Moda }\end{array}$ & $\begin{array}{l}\text { Pergantian } \\
\text { lebih dari satu } \\
\text { moda angkutan } \\
\text { umum }\end{array}$ & \\
\hline \multirow[t]{2}{*}{4} & \multirow{2}{*}{$\begin{array}{l}\text { Lokasi } \\
\text { Prioritas } \\
\text { Penduku } \\
\text { ng } \\
\text { Wisata } \\
\text { Toba }\end{array}$} & TOD System & $\begin{array}{l}\text { Potensial } \\
\text { sebagai Nodes } \\
\text { TOD System }\end{array}$ & \multirow[t]{2}{*}{$\begin{array}{l}\text { Kajian } \\
\text { Literatur } \\
\text { dan Suvey }\end{array}$} \\
\hline & & $\begin{array}{l}\text { Keanekaraga } \\
\text { man potensi } \\
\text { aktifitas } \\
\text { wisata }\end{array}$ & $\begin{array}{l}\text { Memiliki } \\
\text { beberapa } \\
\text { potensi wisata } \\
\text { di sekitar lokasi }\end{array}$ & \\
\hline 5 & $\begin{array}{l}\text { Permuki } \\
\text { man } \\
\text { Penduku } \\
\text { ng Lokasi } \\
\text { Prioritas } \\
\text { Wisata }\end{array}$ & Proximity & $\begin{array}{l}\text { Kedekatan } \\
\text { berdasarkan } \\
\text { jarak dan } \\
\text { memiliki } \\
\text { korelasi } \\
\text { ekonomi }\end{array}$ & Analisis \\
\hline
\end{tabular}

Sumber :Laporan Akhir Perencanaan Kawasan Pariwisata Danau Toba Provinsi Sumatera Utara 2016.

\section{Kajian Teori}

Kajian teori yang digunakan dalam Identifikasi Kawasan Permukiman Pendukung : Analisis Proximity Pengembangan Destinasi Wisata Danau Tobadiawali dengan memahami teori perumahan permukiman Ekistics dari Doxiadis (1974), permukiman merupakan totalitas lingkungan: 1. Alam (nature) 2. Manusia (antropos), 3 masyarakat (society), 4. Ruang Kehidupan (shell) dan 5. Jaringan (network).

Lebih lanjut John Turner (1982) mengatakan bahwa sifat atau karakter permukiman (kota) yang terbentuk sesuai dengan asal daerah pemukim berupa tingkat ekonomi, kehidupan sosial dan budaya. Sifat dan karakter ini akanmenjadi karakter yang dapat menimbulkan 
dampak pada kawasan tempat bermukim baru dan sekitarnya.

Beberapa teori yang menjadi kajian adalah tentang bagaimana melakukan identifikasi dan penjelasan relasi yang berkait dari fakta-fakta atau dalam hal ini adalah keterkaitan dengan Daerah Tujuan Wisata Danau Toba. (Verma and Beard ${ }^{4}$ dalam Judith Bell, 2006 ; Black and Champion, $\left.1999^{6}\right)$.Kajian melalui identifikasi dan penjelasannya inilah yang menjadi rangkuman masukan dalam melakukan analisa menggunakan metoda proximity.

Proxymity sendiri merupakan metoda dari Geographical Information System (GIS) atau Sistem Informasi Geografi (Husein, 2003) ${ }^{7}$ dengan keistimewaan analisa berupa analisa overlay dananalisa proximity. Berikut adalah dua keistimewaan analisa melalui. Analisa overlaymerupakan proses integrasi data dari lapisan-lapisanyang berbeda sedangkan analisa proximity merupakan analisa geografis yang berbasis pada jarak antar layer. Analisa Spasial dilakukan dengan meng-overlay dua peta yang kemudian menghasilkan peta baru hasil analisis.

${ }^{4}$ Kajian kepustakaan dalam teorinya merupakan kegiatan membangun konsep atau struktur teoritis yang mampu menjelaskan fakta dan keterkaitan antar mereka. Formulasi konsep ini mengindikasikan pemikiran atau jalinan yang hilang atau data tambahan yang diperlukan. Judith Bell, Doing your Research Project, Open University Press, McGraw Hill, 2005diterjemahan: penerbit PT Indeks,Gramedia Group,2006.

${ }^{5}$ Judith Bell, Doing your Research Project, Open University Press, McGraw Hill, 2005diterjemahan: penerbit PT Indeks, Gramedia Group,2006.

${ }^{6}$ Black, James A. dan Champion, Dean J., Metoda dan masalah Penelitian Sosial, Penerbit PT Refika Aditama, Bandung 1999 halaman 94

${ }^{7}$ Analisa Proximity merupakan suatu geografi yang berbasis pada jarak antar layer. Dalam analisis proximity SIG menggunakan proses yang disebut dengan buffering (membangun lapisan pendukung sekitar layer dalam jarak tertentu untuk menentukan dekatnya hubungan antara sifat bagian yang ada. Analisis Proximity ini diikuti dengan analisis overlay yaitu proses integrase data dari lapisan-lapisan layer yang berbeda disebut dengan overlay. Secara analisa membutuhkan lebih dari satu layer yang akan ditumpang susun secara fisik agar bisa dianalisa secara visual.

\section{METODOLOGI PENELITIAN Kajian/Riset}

Kajian pada riset Identifikasi Kawasan Permukiman Pendukung : Analisis Proximity Pengembangan Destinasi Wisata Danau Toba merupakan riset Mapping ${ }^{8}$ atau Pemetaan dari variable sesuai dengan kerangka pelaksanaan metoda riset kajian-kajian yang dilakukan mendapatkan rangkuman rangkuman berikut:

\section{Rangkuman Kajian Pemilihan Lokasi Strategis Pendukung Wisata Danau Toba}

\section{Tabel 2. Overlay Penentuan Lokasi Strategis Berdasaran araha Rencana Tata Ruang dan Ketersediaan Bandara}

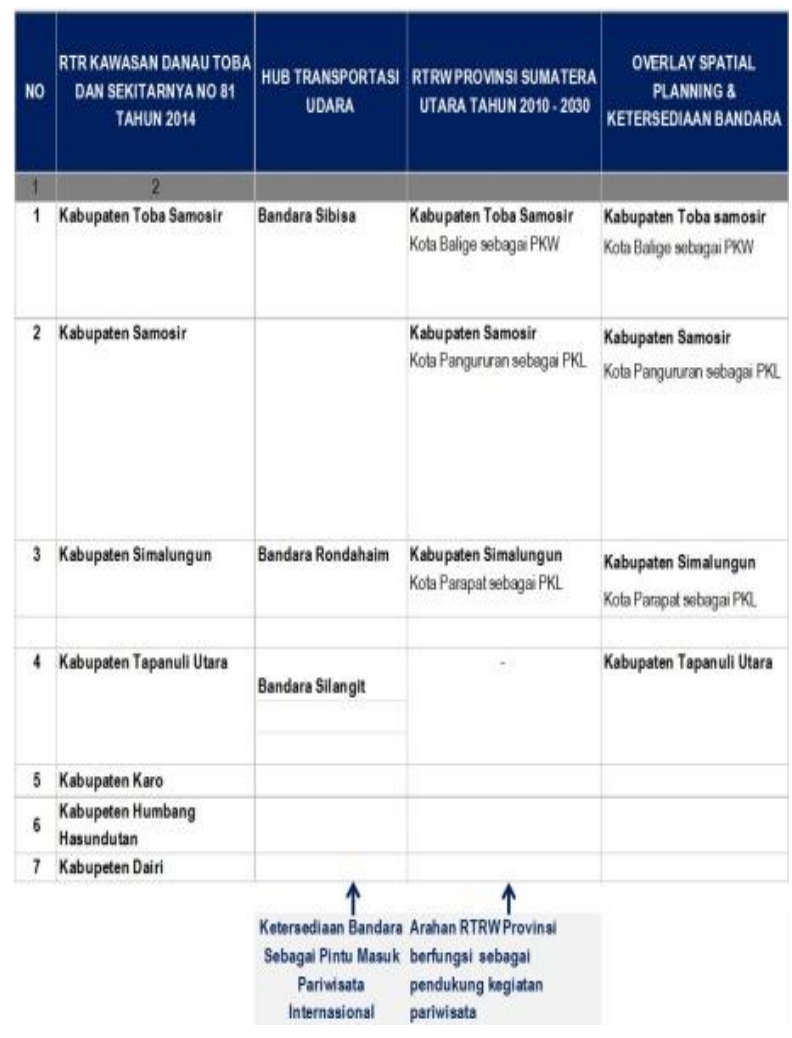

\footnotetext{
${ }^{8}$ Riset dengan metoda Mapping ini merupakan salah satu metoda dalam Riset Kuantitatif dalam Arsitektur.
} 


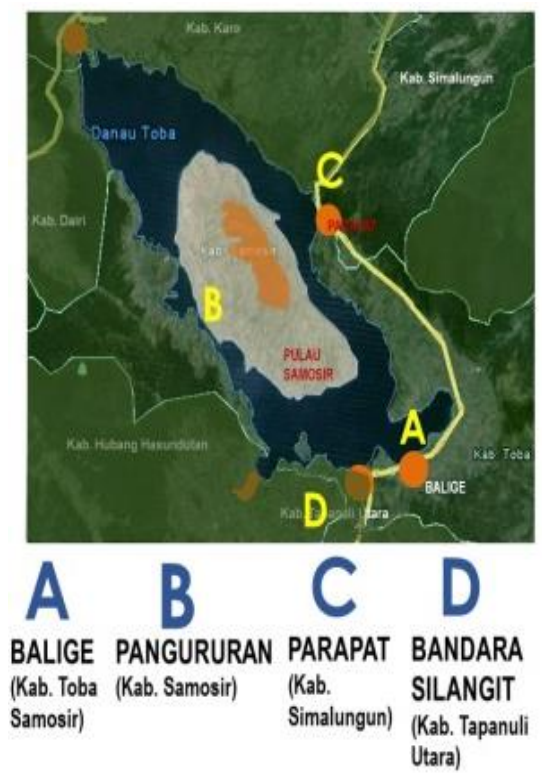

Gambar 2. Overlay Penentuan Lokasi Strategis Berdasaran araha Rencana Tata Ruang dan Ketersediaan Bandara. Sumber: Laporan Akhir Perencanaan Kawasan Pariwisata Danau Toba Provinsi Sumatera Utara 2016.

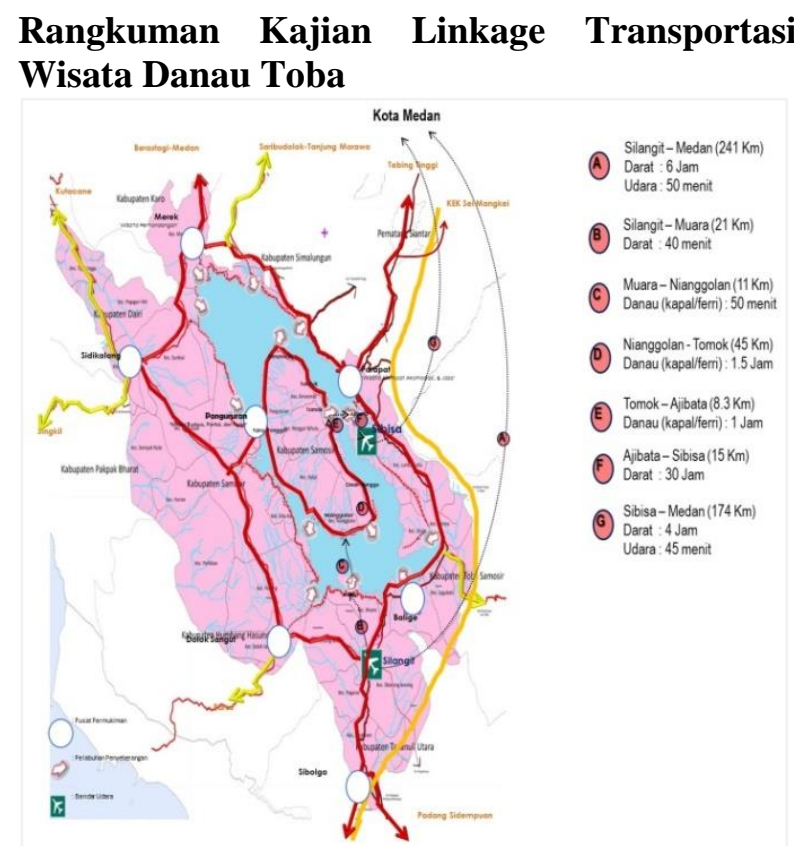

Gambar 3. Peta Alternatif Tourism Linkage Kawasan Danau Toba. Sumber: Laporan Akhir Perencanaan Kawasan Pariwisata Danau Toba Provinsi Sumatera Utara 2016

\section{Rangkuman Kajian Titik Interchange Moda}

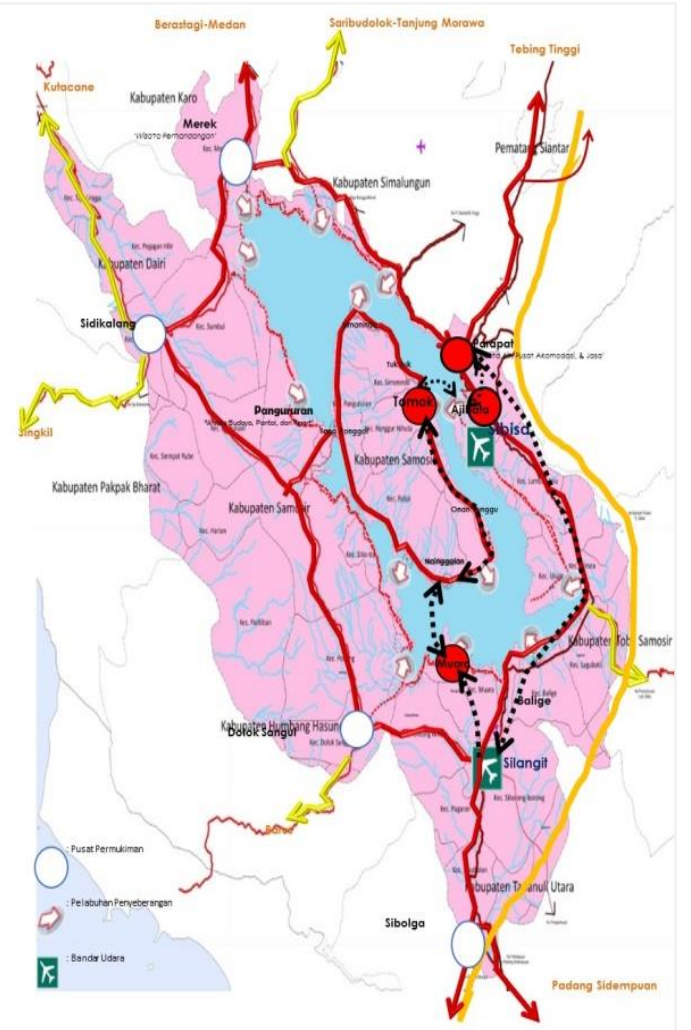

Gambar 4. Peta Nodes Interchange Moda Kawasan Danau yaitu Danau, Geopark, dan Heritage. Sumber: Laporan Akhir Perencanaan Kawasan Pariwisata Danau Toba Provinsi Sumatera Utara 2016.

\section{Analisis}

Analisis riset Identifikasi Kawasan Permukiman Pendukung : Analisis Proximity Pengembangan Destinasi Wisata Danau Tobasecara keseluruhan merupakan analisis pemetaan atau Mapping. Metoda proximityadalah merupakan metoda analisis spasial yang digunakan sebagai pendekatan untuk membangun lapisan penjelasan sekitar layer (DTW Danau Toba) dalam jarak tertentu dari permukiman.Jarak tertentu tersebut digunakan untuk menentukan dekattidaknya hubungan antara sifat bagian yang ada. Dengan kata lain bahwa metoda ini akan mendapatkan penentuan permukiman pendukung wisata Danau Toba. Permukiman pendukung wisata diartikan sebagai kawasan permukiman 
yang memiliki korelasi terhadap obyek wisata berdasarkan kedekatan jarak dan korelasi ekonomi.Sedangkan penggunaan metoda 'Proximity' dapat diartikan seabgai rentang jarak dari obyek wisata yang memeberikan korelasi ekonomi.Konsep metoda tersebut seperti ada gambar di bawah ini.

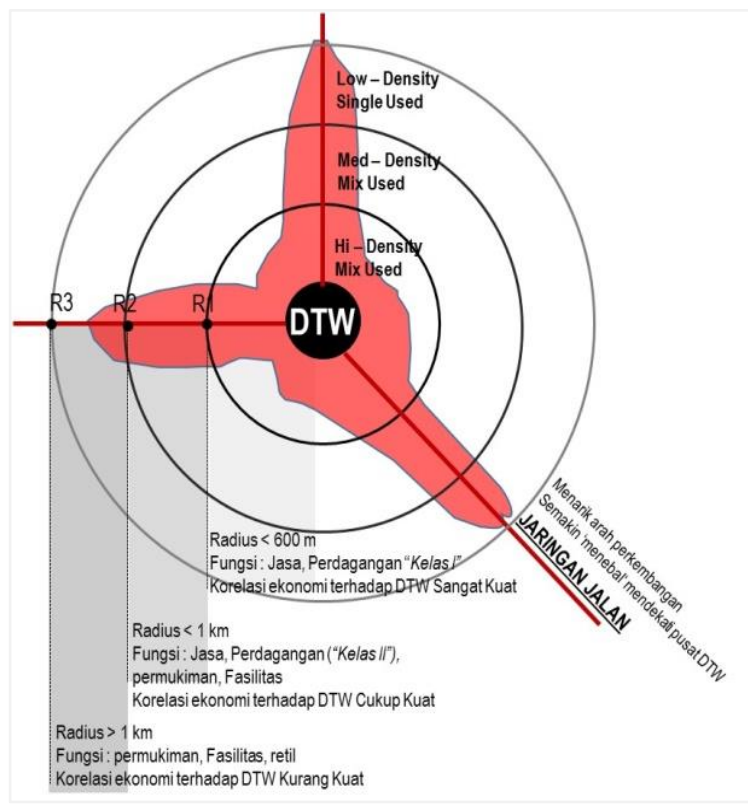

Gambar 5. Konsep Proximity dengan Pola Konsentrik Radial $^{9}$

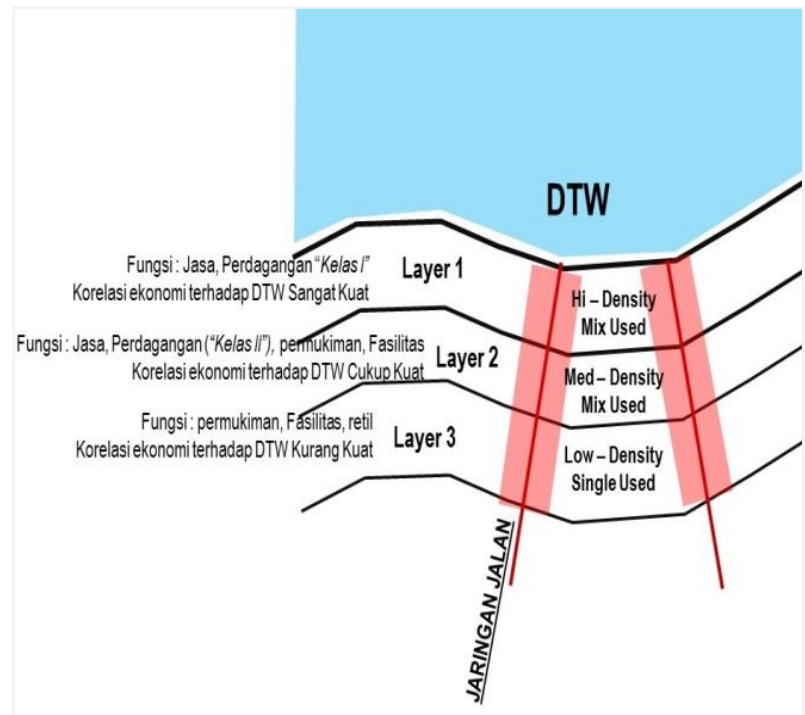

Gambar 6. Konsep Proximity dengan Pola Linear ${ }^{10}$

Hasil dari analisis menggunakan proximity secara spasial didapatkan penentuan kawasan permukiman prioritas pendukung pariwisata Danau Toba.Hal ini berdasarkan variable lokasi strategis, obyek wisata unggulan, tourism linkages pada obyek wisata unggulan, lokasi prioritas pendukung wisata toba dan permukiman pendukung lokasi prioritas wisata. Kawasan Permukiman tersebut adalah:

1. Permukiman Pedukung Wisata Pantai Bebas Parapat;

Permukiman pendukung adalah pada kelurahan Parapat, terdiri dari 3 wilayah 1, 2, \& 4 (lihat peta) dengan obyek wisata berupa: pantai bebas Parapat; wisata tepian danau; geopark dan koridor perdagangan dan jasa.

\footnotetext{
${ }^{10}$ Pada kawasan wisata Danau Toba dimana danau (air) dan geopark (bukit) menjadi pusat obyek wisata maka konsep proximityakan bertransformasi menjadi model layer. Pada layer pertama dengan jarak layer $<600 \mathrm{~m}$ akan tumbuh menjadi kawasan yang memiliki korelasi langsung terhadap wisata Danau Toba, diantaranya adalah perhotelan, taman wisata, pusat belanja, dsb. Di antara pemanfaatanpemanfaatan lahan tersebut, tumbuh kawasan permukiman yang sudah sejak lama tumbuh di kawasan tersebut.
} 


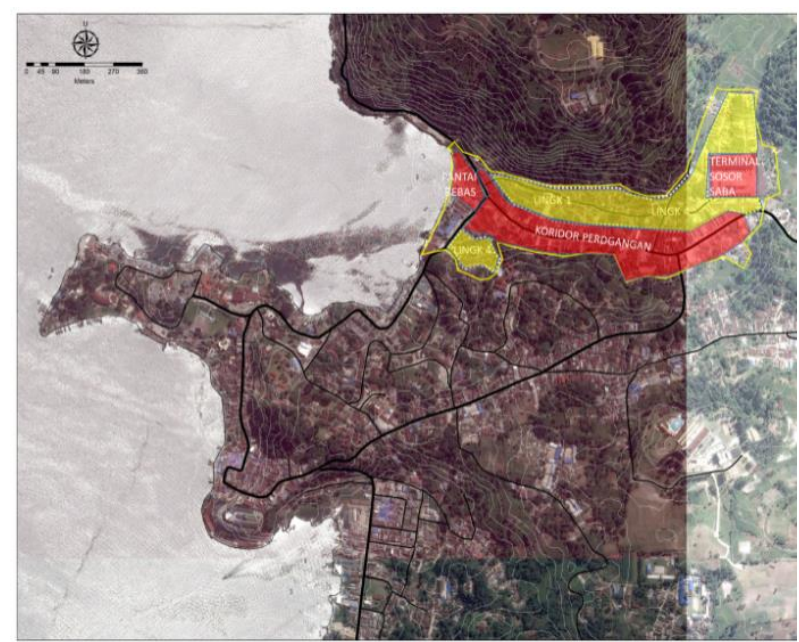

Gambar 7. Peta Permukiman Pedukung Wisata Pantai Bebas Parapat. Sumber: Laporan Akhir Perencanaan Kawasan Pariwisata Danau Toba Provinsi Sumatera Utara 2016.

2. Permukiman Pedukung Interchange Moda Ajibata

Permukiman pendukung adalah di desa pardamean Ajibata, kecamatan Ajibata, Kab Toba Samosir dengan bentuk interchange moda berupa pelabuhan penumpang Ajibata; pelabuhan feri Ajibata; terminal Ajibata; dengan obyek wisata longbeachAjibata; dan pasar Ajibata.

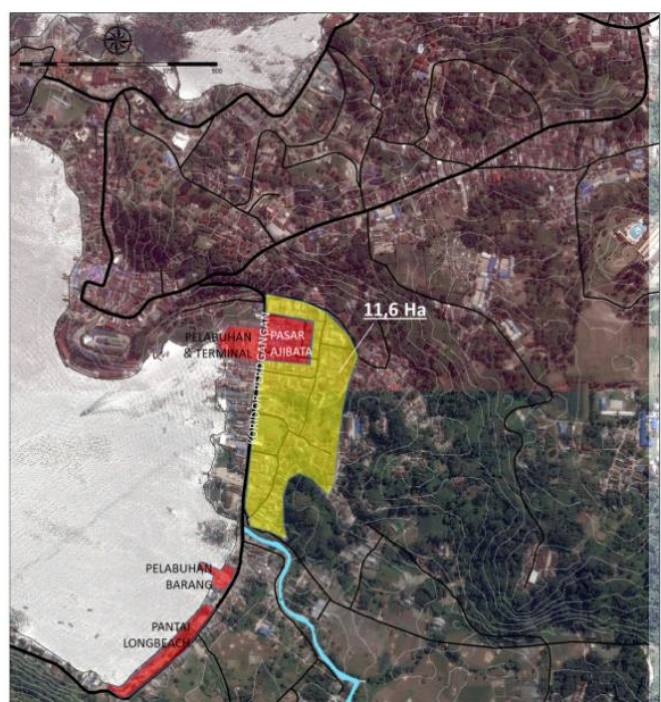

Gambar 8. Peta Permukiman Pedukung Interchange Moda Ajibata. Sumber: Laporan Akhir Perencanaan Kawasan Pariwisata Danau Toba Provinsi Sumatera Utara 2016.

3. Permukiman Pedukung Interchange Moda dan Wisata Tomok

Permukiman pendukung adalah desa Tomok Parsaoran pada interchange modapelabuhan penumpangpelabuhan feri sebagai pelabuhan wisata; dengan obyek wisata berupa rumah adat, museum, souvenir shop, geopark, dan pantai.

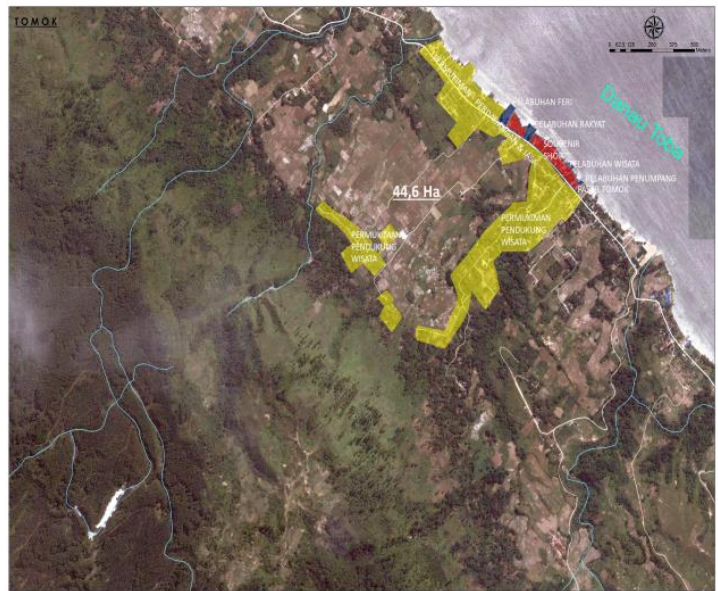

Gambar 9. Peta Permukiman Pedukung Interchange Moda dan Wisata Tomok. Sumber: Laporan Akhir Perencanaan Kawasan Pariwisata Danau Toba Provinsi Sumatera Utara 2016. 
4. Permukiman Pedukung Interchange Moda Muara

Permukiman pendukung di desa Unte Mungkur \& desa Hutana Godang, Kecamatan Muara, Kab Tapanuli Utara; sedangkan interchange moda adalah pada pelabuhan penumpang Muara, pelabuhan feri Muara Nainggolan (Samosir) dan terminal Ajibata. Obyek wisata yang dikembangkan adalah pasar muara, desa-desa wisata, pantai muara, pulau Sibandang dan geopark.

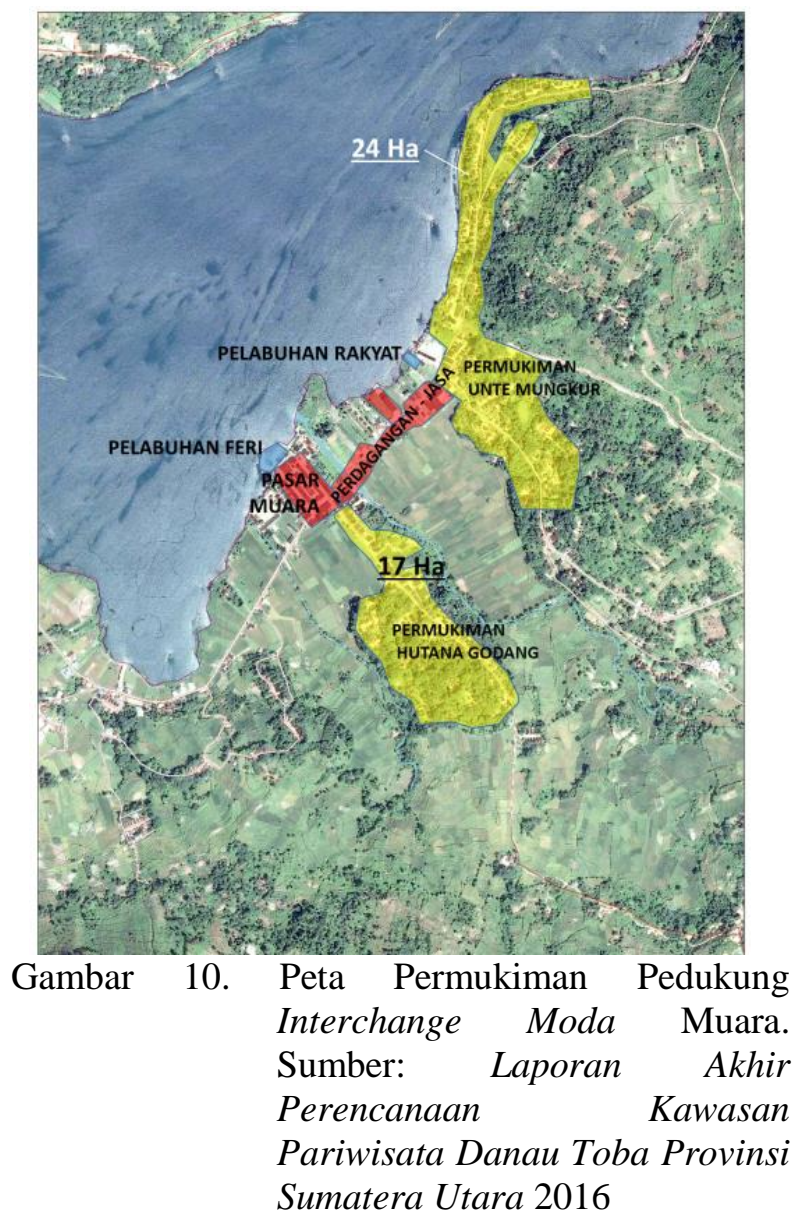

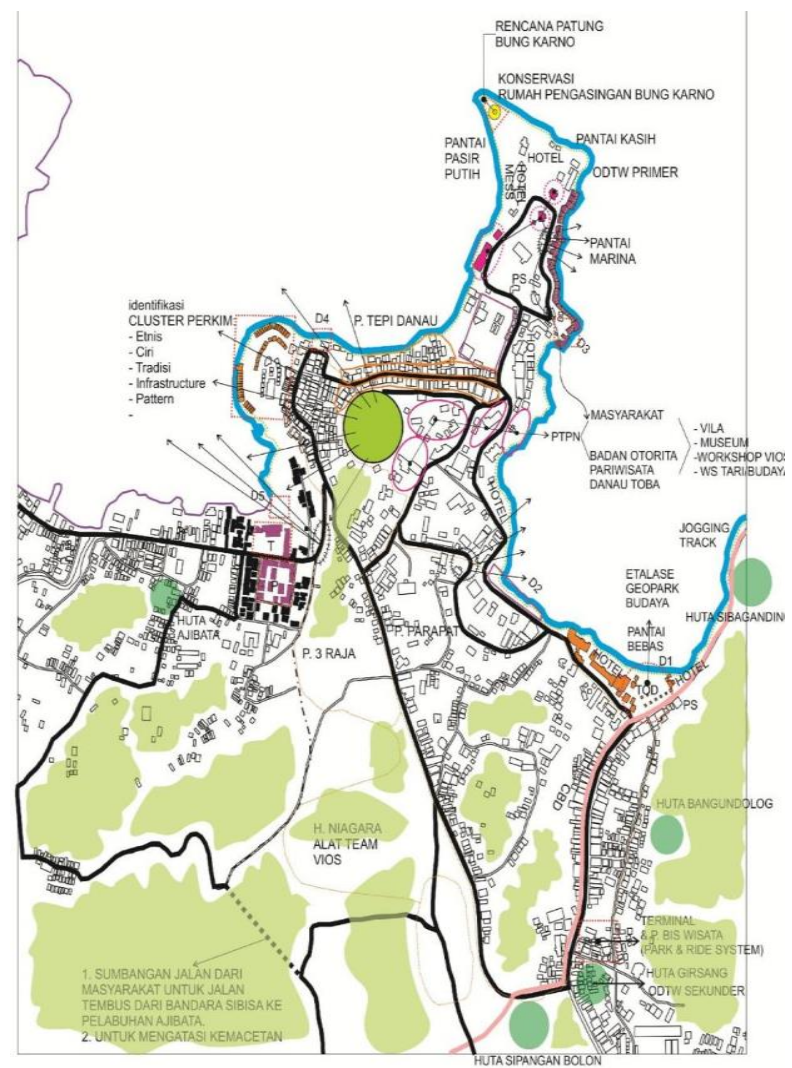

Gambar 11. Konsep Kebutuhan Penanganan Kawasan Permukiman dalam mendukung Kestinasi Wisata Danau Toba. Sumber: Laporan Akhir Perencanaan Kawasan Pariwisata Danau Toba Provinsi Sumatera Utara 2016

\section{SIMPULAN}

Riset yang telah dilakukan menyimpulkan bahwa Identifikasi Kawasan Permukiman Pendukung:Analisis Proximity Pengembangan Destinasi Wisata Danau Tobadapat meningkatkan kapasitas kepariwisataan Danau Toba agar lebih marketable atau memiliki peningkatan daya jual, sebagai Kawasan Strategis Pariwisata. Peningkatan aspek-aspek lingkungan binaan dalam hal ini permukiman menjawab identifikasi kawasan permukiman manasaja yang dapat mendukung pengembangan Desitinasi Wisata Danau Toba.

1. Hasil identifikasi melalui kajian kawasan permukiman mendapatkan kawasan permukiman berperan sebagai pendukung kegiatan wisata. Kawasan Permukiman 
tersebut merupakan interchange moda yang memiliki linkage dengan pusat-pusat layanan jasa pariwisata kota-kota sekitar Danau Toba. Kawasan Permukiman yang diidentifikasikan adalah Permukiman Pedukung Wisata Pantai Bebas Parapat;Permukiman Pedukung Interchange Moda Ajibata; Permukiman Pedukung Interchange Moda dan Wisata Tomok; dan Permukiman Pedukung Interchange Moda Muara.

2. Analisa yang dilakukan dengan menggunakan metoda proximity dapat memetakan rentang jarak dari obyek wisata yang memeberikan korelasi ekonomi. Pemetaan yang dilakukan dengan menggunakan variable lokasi strategis, obyek wisata unggulan, tourism linkages pada obyek wisata unggulan, lokasi prioritas pendukung wisata toba dan permukiman pendukung lokasi prioritas wisata sebagai keterkaitan jasa layanan pariwisata.

3. Dengan demikian dapat merumuskan kebutuhan konsep kebutuhan penanganan kawasan permukiman terkait dengan kepariwisataan Danau Toba berupa (1) Skenario Penanganan Kawasan Prioritas Permukiman Pendukung di Pantai Bebas Parapat, Ajibata, Tomok, Muara yang diikuti dengan (2) Peningkatan Dermaga; (3) Lakefront City (4) Pengembangan Daerah Tujuan Wisata melalui Daerah Tujuan Wisata Primer (Geopark dan Danau Toba) dan Daerah Tujuan WisataSekunder; (5) Parkand RideSystem serta (6) Pengembangan terminal Sosor Saba sebagai terminal wisata dan area parkir bagi wisatawan.

\section{DAFTAR PUSTAKA}

Black, J.A. dan Champion, D. J., 1999, Metoda dan masalah Penelitian Sosial, Penerbit PT Refika Aditama, Bandung.

Budiyanto, 2003, Sistem Informasi Geografis Menggunakan Arc View GIS Yogyakarta, Penerbit Andi, Yogyakarta.

DeMers, Michael N., 2009, GIS For Dummies, Wiley Publishing Inc., Indianapolis

Doxiadis, Constantinos A., 1968, An Introduction to the Science of Human Settlements, Mc Graw Hill Book, New York.
Groat, L. and Wang, D., 2002, Architectural Research Methods, John Wiley \& Sons. Inc., New York.

Prahasta, E., 2002, Konsep-Konsep Dasar Sistem Informasi Geografis, Informatika, Bandung.

Turner, J., 1976, Housing by People; Towards Autonomy in Building Environments, Mario Boyars London Boston

Aqli, W., 2004, Analisa Sistem Informasi Geografis untuk Identifikasi Kawasan Permukiman Rawan Banjir di Bantaran Sungai. Jurnal Ilmiah Penelitian LPPM Universitas Muhammadiyah Jakarta, Universitas Muhammadiyah, Jakarta.

Kementerian Pekerjaan Umum Perumahan Rakyat, 2016, Laporan Akhir Perencanaan Kawasan Pariwisata Danau Toba, Provinsi Sumatera Utara, Medan.

Permen PUPR NO.2/PRT/M/2016 tentang Peningkatan Kualitas terhadap Perumahan Kumuh dan Permukiman Kumuh. 